\title{
OS POLIMORFOS DE CARBONATO DE CÁLCIO - UMA SÍNTESE FÁCIL DE ARAGONITA
}

\author{
Karl E. Bessler* e Laécio C. Rodrigues \\ Instituto de Química, Universidade de Brasília, CP 04478, 70904-970 Brasília - DF, Brasil
}

Recebido em 21/3/07; aceito em 21/6/07; publicado na web em 19/12/07

\begin{abstract}
THE POLYMORPHS OF CALCIUM CARBONATE - AN EASY SYNTHESIS OF ARAGONITE. Aragonite is a metastable polymorph of calcium carbonate. The calcareous exoskeletons of some organisms like corals or molluscs consist essentially of aragonite. The questions of how, and why these organisms prefer the thermodynamically unstable aragonite for the construction of their hard shells are discussed. The importance of the biomineralization process for the development of new materials is outlined. In the experimental part, a very simple synthesis of polycrystalline aragonite is performed, using carbonated mineral water available at the market. The synthesized aragonite is easily identified by its infrared spectrum.
\end{abstract}

Keywords: polymorphism; aragonite; synthesis.

\section{INTRODUÇÃO}

$\mathrm{O}$ carbonato de cálcio $\left(\mathrm{CaCO}_{3}\right)$ apresenta-se em três modificações minerais. A calcita é um dos minerais mais comuns, sendo o constituinte principal de vastas formações de rochas sedimentares de calcário. O mineral aragonita foi descoberto e identificado, em 1797, na região de Aragón, Espanha, de onde veio o seu nome. A ocorrência de aragonita está vinculada a determinadas circunstâncias físico-químicas durante sua formação. Por exemplo, é freqüentemente encontrado em depósitos calcários que resultam de águas termais. $\mathrm{O}$ terceiro polimorfo, a vaterita, é um mineral bem mais escasso. Um resumo completo sobre o polimorfismo calcita/ aragonita, considerando a literatura até 1971, encontra-se em Lippmann ${ }^{1}$. Historicamente, a ocorrência de carbonato de cálcio em forma dos dois minerais, calcita e aragonita, foi um dos primeiros e mais discutidos exemplos de polimorfismo'. Em 1893, Le Chatelier aplicou às propriedades físicas desses dois polimorfos o princípio que hoje leva o seu nome ${ }^{2}$. Considerando que a aragonita é mais densa que a calcita e aquela se transforma irreversivelmente em calcita a $400{ }^{\circ} \mathrm{C}$, Le Chatelier concluiu que a aragonita deveria ser termodinamicamente estável a baixa temperatura e alta pressão. Dados e cálculos mais recentes mostram que à pressão atmosférica, calcita é a modificação termodinamicamente estável em todas as temperaturas e, que a $25^{\circ} \mathrm{C}$, aragonita se torna estável somente acima de 2900 atmosferas de pressão ${ }^{1}$.

Para sintetizar a aragonita não se precisa recorrer a altas pressões. Em princípio, temos duas opções para precipitar carbonato de cálcio a partir de soluções aquosas. A primeira consiste simplesmente em adicionar um carbonato solúvel a uma solução contendo um sal solúvel de cálcio (Equação 1).

$\mathrm{Ca}^{2+}{ }_{(\mathrm{aq})}+\mathrm{CO}_{3}{ }^{2-}$ (aq) $\longrightarrow \mathrm{CaCO}_{3(\mathrm{~s})}$

$\mathrm{Na}$ segunda, $\mathrm{CaCO}_{3}$ é solubilizado em água saturada com $\mathrm{CO}_{2}$, formando $\mathrm{Ca}\left(\mathrm{HCO}_{3}\right)_{2}$ (Equação 2). Quando o gás carbônico é liberado dessa solução para a atmosfera, a reação se inverte com reprecipitação de $\mathrm{CaCO}_{3}$.

$\mathrm{CaCO}_{3(\mathrm{~s})}+\mathrm{CO}_{2(\mathrm{aq})}+\mathrm{H}_{2} \mathrm{O} \longrightarrow \mathrm{Ca}\left(\mathrm{HCO}_{3}\right)_{2(\mathrm{aq})}$

*e-mail: bessler@unb.br
Apesar da calcita ser a modificação termodinamicamente estável em todas as temperaturas, a tendência de formação de aragonita a partir de soluções aquosas aumenta com a temperatura. Desta maneira, quando a precipitação é realizada próxima à temperatura de ebulição da água, o precipitado consiste predominantemente de aragonita. A obtenção da modificação meta-estável aragonita é atribuída a efeitos cinéticos, isto é, nessas condições tanto a nucleação como o crescimento dos cristais de aragonita acontece mais rapidamente em comparação à calcita. Ainda foi evidenciado que a presença de cátions de $\mathrm{Mg}^{2+}$ na solução favorece a formação de aragonita enquanto outros cátions ou ânions não apresentam esse efeito ${ }^{1}$.

\section{Biomineralização}

É bem conhecido que diversos organismos utilizam carbonato de cálcio como "material de construção" para as partes duras (exoesqueletos ou cascas de ovos). Observa-se que os exoesqueletos carbonáticos de corais e moluscos (conchas, Figuras 1 e 2) consistem preferencialmente de aragonita. As cascas de ovos de aves são formadas quase exclusivamente de calcita, enquanto os ovos de répteis têm casca de aragonita. Muitas vezes o material é constituído de compósitos em camadas alternadas de calcita, aragonita e matéria orgânica (proteínas). Exemplos bem conhecidos desses sofisticados compósitos são a madrepérola e as pérolas das ostras, apreciadas pelos seus brilhos irisantes inconfundíveis. Como é que esses organismos conseguem "driblar" a termodinâmica depositando aragonita a temperatura ambiente? A explicação clássica é que a nucleação de aragonita acontece na superfície de membranas proteínicas que possuem morfologia adequada, atuando como matrizes. Estudos mais recentes revelam que a nucleação é induzida seletivamente (calcita ou aragonita) por proteínas polianiônicas solúveis, próprias dos respectivos organismos ${ }^{3}$. Outra questão interessante é, por que alguns organismos preferem a aragonita para construir suas cascas? Certamente a aragonita apresenta alguma vantagem relacionada com a sobrevivência das espécies que, ao longo de milhões de anos de evolução, "aprenderam" a criar esse material. Qual seria essa vantagem? As propriedades físicas dos dois polimorfos são muito semelhantes (Tabela 1). A densidade e a dureza da aragonita são um pouco superiores àquelas da calcita, fato que não representa uma vantagem significativa. Talvez a resposta esteja na forma dos cristais. Os cristais aciculares de aragonita 


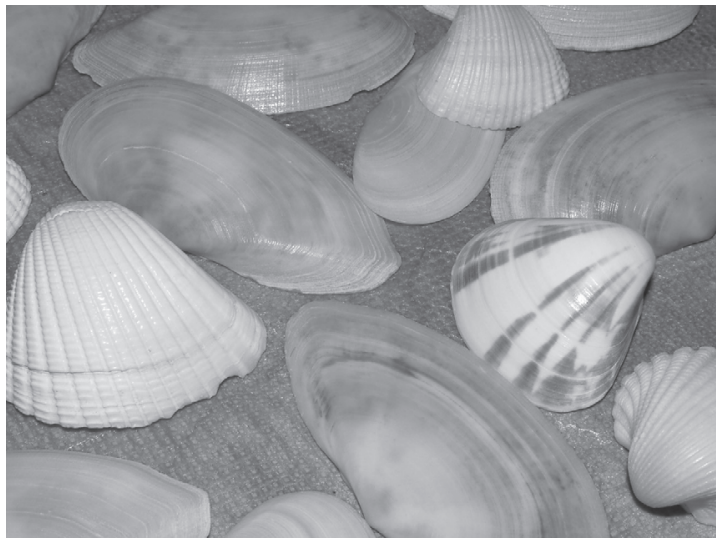

Figura 1. Diversas conchas de bivalves encontradas na praia

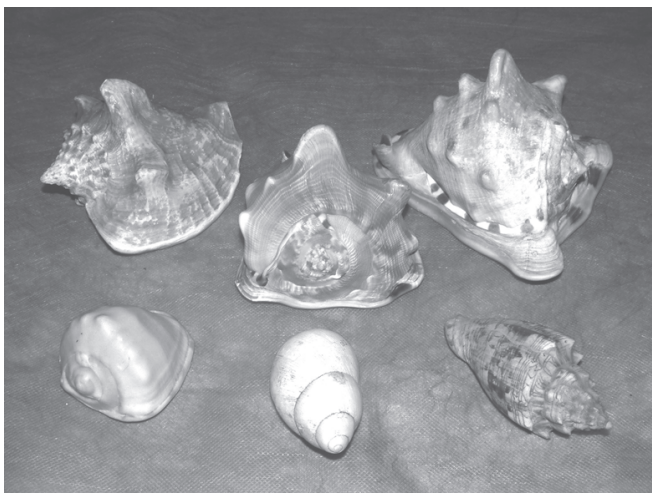

Figura 2. Diversas conchas de caramujos encontradas na praia

são propensos a formar conjuntos entrelaçados. Desta maneira, o material policristalino de aragonita apresenta um considerável aumento de solidez ou maior resistência à quebra. Quem não conhece os "caramujos de porcelana" (Figura 2) que os pescadores vendem na praia como lembranças? A textura micro- ou nanoestruturada proporciona ainda um ganho de solidez a esses materiais. As biocerâmicas têm provocado interesse no desenvolvimento de novos materiais. Nos últimos anos, um número considerável de pesquisas foi dedicado à elaboração de metodologias para obtenção de partículas de aragonita com morfologias específicas, semelhantes àquelas encontradas nas biocerâmicas (síntese biomimética) ${ }^{5-7}$.

\section{Espectros no infravermelho}

Calcita e aragonita podem ser facilmente distinguidas pelos seus espectros de absorção no infravermelho ${ }^{8}$; inclusive misturas dos dois minerais podem ser analisadas quantitativamente por esta técnica ${ }^{9}$. A aplicação deste método é vantajosa em comparação com a difratometria de raios $X$, pois se precisa somente de $2 \mathrm{mg}$ de substância. Além disso, um espectro é obtido em poucos minutos (incluso o tempo de preparação da amostra). A seguir, explica-se porque é possível distinguir os dois polimorfos pelos espectros de infra-vermelho, apesar de que nos dois casos é o mesmo ânion carbonato que se manifesta nos espectros ${ }^{10}$.

$\mathrm{O}$ ânion carbonato tem a estrutura trigonal plana (simetria $D_{3 h}$ ) e possui quatro vibrações fundamentais (Tabela 2). No ânion carbonato livre, não perturbado, apenas três vibrações são observadas. Por motivo de simetria, a vibração $v_{1}$ é inativa no infravermelho, porém, é observada no efeito Raman. No estado sólido, em conseqüência das interações com os átomos da vizinhança, observam-se diversas alterações nos espectros. Em primeiro lugar podem ocorrer variações nas freqüências de vibração. Mudanças mais drásticas originam-se em consequiência das simetrias distintas do íon carbonato nos retículos cristalinos em relação à simetria do íon isolado.

No espectro da calcita aparecem apenas as três vibrações esperadas para o carbonato livre com as freqüências deslocadas (Tabela 2). Isto se deve ao fato que a simetria do retículo é compatível com a simetria trigonal do íon carbonato. Em comparação, o espectro da aragonita apresenta algumas diferenças. Além das alterações das frequiências de $v_{2}$ e $v_{3}$, observa-se o surgimento de uma banda correspondente à vibração $v_{1}$, ausente no espectro da calcita e, a vibração $v_{4}$ aparece desdobrada em dois componentes. $\mathrm{O}$ comportamento de $v_{1}$ e $v_{4}$ deve-se ao fato da simetria do íon carbonato na estrutura cristalina ser menor que a simetria do íon carbonato livre. Em conseqüência, $v_{1}$ torna-se ativa no IV e ocorre o levantamento da degenerescência do modo $v_{4}$, o qual se desdobra em duas bandas. $\mathrm{O}$ mesmo comportamento é esperado para $v_{3}$, porém, o desdobramento não pode ser observado devido à largura da banda espectral. Maiores informações sobre os espectros vibracionais de carbonatos minerais podem ser encontradas no excelente livro de Farmer ${ }^{11}$.

Tabela 1. Algumas propriedades físicas de calcita e aragonita ${ }^{1,4}$

\begin{tabular}{lll}
\hline Mineral & Calcita & Aragonita \\
\hline Densidade / $\mathrm{g} \mathrm{cm}^{-3}$ & 2,711 & 2,944 \\
Dureza (Mohs) & 3 & $3,5-4$ \\
Sistema cristalino - grupo espacial & Trigonal - R $\overline{3} \mathrm{c}$ & Ortorrômbico - Pnma \\
Forma cristalina mais comum & Romboedros ou prismas & Prismas aciculares \\
Número de coordenação do Ca & 6 (octaédrico) & 9 \\
Distância média Ca-O / pm & 236 & 252,8 \\
Solubilidade em $\mathrm{H}_{2} \mathrm{O}$ pura $\left(\mathrm{pK}_{\mathrm{s}}\right)$ a $25^{\circ} \mathrm{C}$ e 1 bar & 8,35 & 8,22 \\
\hline
\end{tabular}

Tabela 2. Vibrações fundamentais do ânion carbonato observadas nos espectros no infravermelho de calcita e aragonita (valores em $\mathrm{cm}^{-1}$ )

\begin{tabular}{|c|c|c|c|c|}
\hline Denominação das vibrações & Simetria & $\mathrm{CO}_{3}^{2-}$ em solução ${ }^{10}$ & Calcita & Aragonita \\
\hline$v_{1}-$ Estiramento simétrico $v_{s}(\mathrm{CO})$ & $A_{1}$ & --- & --- & 1083 \\
\hline$v_{2}$ - Deformação angular fora do plano $\gamma\left(\mathrm{CO}_{3}\right)$ & $\mathrm{A}_{2}$, & 880 & 876 & 857 \\
\hline$v_{3}$ - Estiramento anti-simétrico $v_{a s}(C O)$ & $\mathrm{E}^{\prime}$ & 1451 & 1420 & 1474 \\
\hline$v_{4}$ - Deformação angular no plano $\delta_{d}(\mathrm{OCO})$ & $\mathrm{E}^{\prime}$ & 701 & 712 & $712 / 700$ \\
\hline
\end{tabular}




\section{PARTE EXPERIMENTAL}

\section{Princípio}

A síntese da aragonita é realizada em duas etapas:

1) preparação de uma solução de bicarbonato de cálcio por solubilização de carbonato de cálcio em água saturada com dióxido de carbono (água mineral gaseificada, adquirida no mercado).

$\mathrm{CaCO}_{3 \text { (calcita) }}+\mathrm{CO}_{2 \text { (aq) }}+\mathrm{H}_{2} \mathrm{O} \longrightarrow \mathrm{Ca}\left(\mathrm{HCO}_{3}\right)_{2(\mathrm{aq})}$

2) Precipitação de $\mathrm{CaCO}_{3}$ em forma de aragonita por aquecimento da solução acima de $80^{\circ} \mathrm{C}$.

$\mathrm{Ca}\left(\mathrm{HCO}_{3}\right)_{2 \text { (aq) }} \longrightarrow \mathrm{CaCO}_{3 \text { (aragonita) }}+\mathrm{H}_{2} \mathrm{O}+\mathrm{CO}_{2(\mathrm{~g})}$

\section{Materiais e equipamentos}

Carbonato de cálcio p.a. precipitado em pó; amostras de águas minerais gaseificadas do mercado (embalagens de 400-600 mL); banho-maria; espectrômetro de infravermelho; um microscópio (opcional).

\section{Procedimento}

Adicione rapidamente $500 \mathrm{mg}$ de carbonato de cálcio à garrafa de água gaseificada e feche-a imediatamente. Agite a garrafa vigorosamente e deixe-a em repouso durante alguns dias, com agitação ocasional, até a completa solubilização do $\mathrm{CaCO}_{3}$. Retire uma alíquota de $100 \mathrm{~mL}$ da solução sobrenadante e aqueça a mesma imediatamente em banho-maria acima de $80{ }^{\circ} \mathrm{C}$ durante $2 \mathrm{~h}$.

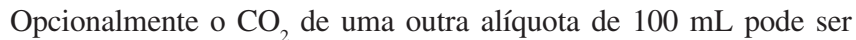
eliminado a temperatura ambiente, passando uma corrente de nitrogênio até se observar a precipitação de $\mathrm{CaCO}_{3}$ (aproximadamente $2 \mathrm{~h}$ ), secar o precipitado e registrar um espectro no infravermelho. Neste caso o produto é calcita em vez de aragonita. Após esfriar, decante e descarte o líquido sobrenadante e seque o precipitado na estufa durante $30 \mathrm{~min}$ a $120{ }^{\circ} \mathrm{C}$. Se tiver um microscópio disponível, observe a morfologia do sólido obtido. A aragonita apresentase sob forma de agulhas entrelaçadas (Figura 3), ao contrário da calcita, que cristaliza em blocos isolados.

Registre um espectro no infravermelho (na faixa de 4000 a 400 $\mathrm{cm}^{-1}$ ) do sólido (pastilhas em $\mathrm{KBr}$ de $2 \mathrm{mg}$ da amostra). Identifique o produto comparando o espectro obtido com os espectros de referência de calcita e de aragonita (Figura 4).

\section{RESULTADOS}

O experimento foi realizado com sucesso por alunos da disciplina Laboratório de Química Inorgânica do Curso de Graduação em Química da Universidade de Brasília no ano letivo de 2006. Pelo método descrito são obtidos de 60 a $70 \mathrm{mg}$ de produto por cada amostra de água, mais que suficiente para sua caracterização. Em seis amostras de diferentes marcas de água mineral ou água gaseificada encontradas no mercado, os produtos obtidos foram identificados pelos seus espectros no infravermelho como aragonita.

\section{AGRADECIMENTOS}

Agradecemos à Profa. S. N. Báo, Universidade de Brasília, por facilidades de microscopia e ao Prof. E. Gierth, Universidade Técnica de Clausthal, por uma amostra autêntica de aragonita mineral.

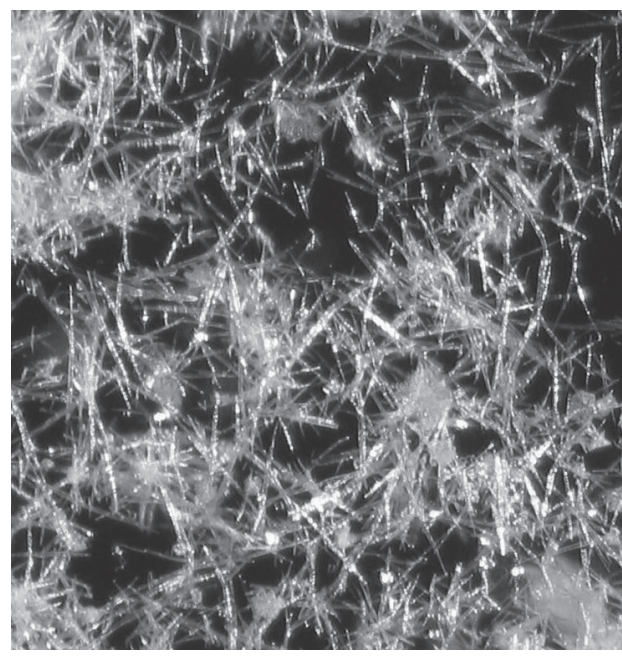

Figura 3. Microfotografia de aragonita sintética mostrando conjuntos entrelaçados de cristais aciculares

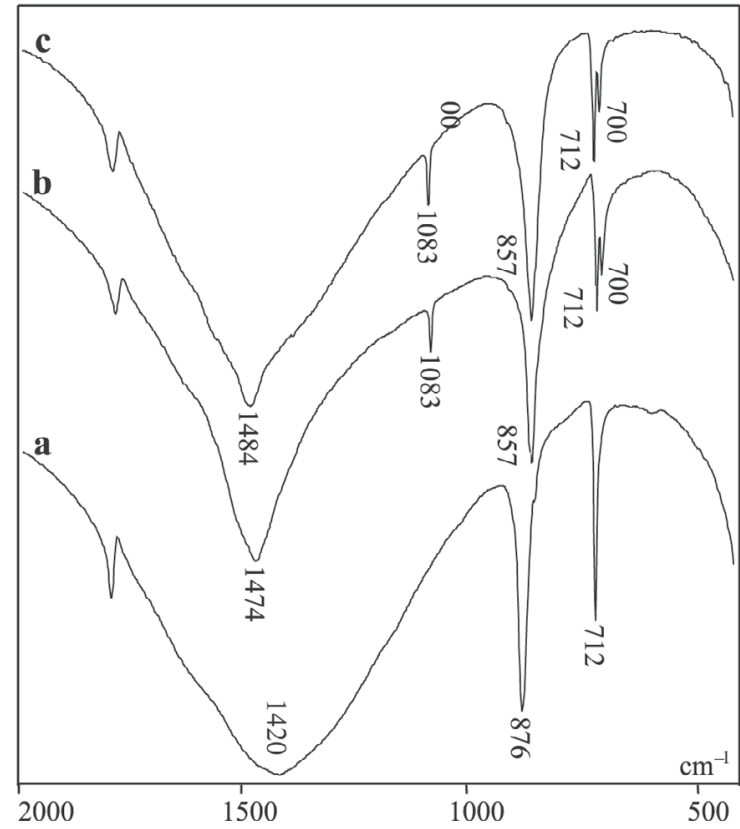

Figura 4. Espectros no infravermelho (pastilhas de $\mathrm{KBr}$ ) de diversas amostras de $\mathrm{CaCO}_{3}$ a: calcita precipitada, b: aragonita mineral, c: amostra de aragonita obtida neste experimento

\section{REFERÊNCIAS}

1. Lippmann, F.; Sedimentary Carbonate Minerals, Springer: Berlin, 1973.

2. Le Chatelier, H.; Compt. Rend. 1893, 116, 390.

3. Belcher, A. M.; Wu, X. H.; Christensen, R. J.; Hansma, P. K.; Stucky, G. D.; Morse, D. E.; Nature 1996, 381, 56.

4. http://www.mindat.org, acessada em Janeiro 2007.

5. Mukkamala, S. B.; Anson, C. E.; Powell, A. K.; J. Inorg. Biochem. 2006 100, 1128.

6. Nassif, N.; Gehrke, N.; Pinna, N.; Shirshova, N.; Tauer, K.; Antonietti, M.; Colfen, H.; Angew. Chem., Int. Ed. 2005, 44, 6004.

7. Zhang, X.; Zhang, Z.; Yan, Y.; J. Cryst. Growth 2005, 274, 550.

8. Adler, H. A., Kerr, P. F.; Am. Mineral. 1962, 47, 700

9. Labbé, J. P.; Bédiang, B.; Lédion. J.; Analusis 1984, 12, 514

10. Weidlein, J.; Müller, U.; Dehnicke, K.; Schwingungsspektroskopie - Eine Einführung, Georg Thieme Verlag: Stuttgart, 1982.

11. Farmer, V. C., ed.; The Infrared Spectra of Minerals, Mineralogical Society, London, 1974. 